\title{
PENDIDIKAN MULTIKULTURAL DALAM BINGKAI ISLAM NUSANTARA PERSPEKTIF KH. SAID AQIL SIROJ
}

\author{
Hasan Baharun \\ Universitas Nurul Jadid, Paiton, Probolinggo, Jawa Timur \\ ha54nbaharun@gmail.com \\ Farah Nuril Badriyah \\ Universitas Nurul Jadid, Paiton, Probolinggo, Jawa Timur \\ farahnb@gmail.com
}

\begin{abstract}
This study aims to analyze the thinking of $\mathrm{KH}$. Said Aqil Siroj about multicultural education in the frame of Islam Nusantara, where KH. Said Aqil Siroj is a phenomenal figure in the community, and has an open mind to the dynamics of differences in Indonesia. This study uses a qualitative approach with library research, in which researchers attempt to collect data derived from books, scientific journals, speeches and statements of KH. Said Aqil Siroj in various media, both print and electronic media, and other documents. The data analysis technique uses content analysis. The results showed that; multicultural education in the frame of Islam Nusantara Islam, according to KH. Said Aqil Siroj can be implemented in a way; mobilize and optimize the role of Kiai in the community, strengthen the curriculum in Islamic educational institutions based on multiculturalism, carry out regeneration to strengthen organizational solidarity, and instill and teach the attitude of nationalism to the community
\end{abstract}

Keywords: Multicultural Education, Islam Nusantara, KH Said Aqil Siroj 


\section{Pendahuluan}

Manusia memegang otoritas untuk mengemban tugas pendidikannya serta menyandang sebuah kemampuan atau potensi untuk mengaplikasikannya pada rutinitas kesehariannya. Karenanya, pendidikan dianggap tanggung jawab wali murid, pemerintah, guru, termasuk juga masyarakat. ${ }^{1}$ Masyarakat sekitarlah yang berperan besar menyokong pendidikan. Maka, partisipasi masyarakat untuk mensukseskan unit-unit yang bersifat edukasi sangatlah diperlukan demi menegakkan dinamisme suatu negara.

Orientasi pendidikan adalah pembentukan dan penyusun behavior seseorang menuju insan peradaban. Tak selesai di situ, Pendidikan terlihat sebagai sarana mendidik, membimbing, mengasuh generasi putra dan putri bangsa berharap menjadi warga yang balance antara kehidupan dunia-akhirat. ${ }^{2}$ Saat inipun, eksitensi pendidikan bernuansa Islam tetap kukuh. Akibatnya, tidaklah dapat dipungkiri lagi kebenarannya bahwa sekte Islam dalam ruang lingkup pendidikan merupakan instusi yang menanamkan dan mengajarkan komponen-kompoen Islam untuk diproklamirkan sebagai ajaran absolute dan bentuk keyakinan. ${ }^{3}$

Warga Indonesia adalah berdinamika dan multicultural. Ini sebanding dengan konteks keindonesiaan maka, mencari pendidikan alternatif secara mutlak sangat diperlukan. ${ }^{4} \quad$ Indonesia terdiri dari masyarakat yang plularis dan multikulturalis ${ }^{5}$ karenanya, Indonesia memerlukan instrument yang bisa dijadikan pergerakan nasionalisme bangsa. Orientasinya, Indonesia menjadi berkelas, bermartabat dan berdaulat. Kiranya, perlu sistem untuk mengakomodasi keberagaman, salah satunya melalui dunia pendidikan. ${ }^{6}$

Keragaman dan ketidakserasian itu sebagai instrumen untuk mempererat keharmonisan bersama. Namun faktanya, suatu diferensia

\footnotetext{
${ }_{1}$ M. Faisol, 'Peran Pondok Pesantren Dalam Membina Keberagaman Santri', AlTanzim: Jurnal Manajemen Pendidikan Islam, 1.2 (2017), 37-51 <https://doi.org/10.1017/CBO9781107415324.004>.

2 Abdurahman, 'Implikasi UUSPN Terhadap Pendidikan Islam', Al-Tanzim: Jurnal Manajemen Pendidikan Islam, 1.1 (2017), 19-35.

${ }^{3}$ Ramayulis, "Ilmu Pendidikan Islam," (Jakarta Kalam Mulia), 4.

${ }^{4}$ Eko Setiawan, "Pemikiran Abdurrahman Wahid Tentang Prinsip Pendidikan Islam Multikultural Berwawasan Keindonesiaan," Jurnal Pendidikan Islam, 2.1 (2017), 1-14.

5 Chusnul Muali, "Rasionalitas Konsepsi Budaya Nusantara dalam Menggagas Pendidikan Karakter Bangsa Multikultural,” Jurnal Islam Nusantara, 1.1 (2017), 1-13.

${ }^{6}$ Kuswaya Wihardit, "Pendidikan Multikultural: Suatu Konsep, Pendekatan dan Solusi," Jurnal Pendidikan,11.11 (2010), 1-10.
} 
justru memicu adanya suatu konflik. ${ }^{7}$ Melihat kenyataan tersebut, paradigma Kiai Said sepertinya pantas dan singkron untuk dijadikan sistem nasional dalam mengatasi terjadinya beberapa konflik dan menyatukan keberagaman yang ada. Beliau termasuk pencetus term "Islam Nusantara" di Indonesia. Islam Nusantara adalah ciri khas Indonesia di mana nilai-nilai keIslaman tetap tergaja sekalipun dipenuhi banyak agama serta budaya yang ada.

Kiai Said juga merupakan tokoh besar NU yang berperan dan aktif dalam menjadikan dan mewujudkan Indonesia sejahtera. Masyarakat sangat mengakui dakwahnya yang meniti jalur hubungan horizontal yang bak aroma kasturi, sampai-sampai beliau diberi lebel agama yang berbeda-beda. Kerangka hidup yang kokoh akan pendidikan agama dan mempunyai semangat yang gigih untuk memperjuangkan Islam di era globalisasi ini, termasuk pedoman yang dipegang oleh beliau hingga dapat membagikan dampak dan skala positif terhadap perkembangan masyarakat Indonesia.

Terdapat beberapa penelitian yang mengurai tentang pendidikan multikultural; Penelitian $\mathrm{Nadli}^{8}$ yang menyatakan bahwa keharmonisan kehidupan antar umat beragama dan berbangsa semakin hari semakin terancam. Oleh karena itu, menjadi penting menginternalisasikan konsepkonsep multikultural oleh sekelompok penduduk sekitar sehingga, memerlukan untuk diberlakukannya dogma pendidikan multikultural dari intelektual dan ilmuwan.

Ambaruddin ${ }^{9}$ juga menyatakan bahwa Indonesia memerlukan pendidikan multikultural harapannya, meminimalisir terjadinya problem dan persengketaan ummat. Orang-orang mengetahui akan jalan keluar terciptanya kerukunan bangsa, akan tetapi perilaku dan keadaan lingkungan mayoritas masyarakat yang berdasar pada sikap multikultural masih jauh dari yang diharapkan karenanya, memerlukan solusi serta upaya cermat dan tepat untuk memupuk semangat pada warga Indonesia, supaya dapat terealisasi sebuah keharmonisan.

Kajian Fadlullah ${ }^{10}$ juga menyimpulkan tentang pilar-pilar paham Aswaja harus dipertahankan. Walaupun tidak senada dengan ajaran

\footnotetext{
7 Endah R. Chotim Irwandi, "Analis Konflik Antara Masyarakat,Pemerintah dan Swasta," Jurnal JISPO, 7. 2 (2017), 1-20.

8 M.Nadlir, "Pendidikan Multikultural Dalam Perspektif Said Agil Husin Al Munawwar," Jurnal Pendidikan Agama Islam, 1.1 (2013), 1-17.

9 R. Ibnu Ambarudin, "Pendidikan Multikultural untuk Membangun Bangsa yang Nasionalis Religius," Jurnal Civis,13. 1 (2016), 1-18.

10 Muhammad Endy Fadlullah, "Ahlu Al-Sunnah Wa Al-Jamaah dalam Perspektif Said Aqil Siradj," Jurnal Nidhomul Haq, 3.1 (2018), 1-11.
} 
Imam Abu Hasan dan Imam Al Maturidi. Dalam artian, berbedanya argumen dalam menginterpretasikan sumber agama selama masih berpedoman dengan pilar-pilar Aswaja jauh kemungkinan akan terpisahkan.

Berangkat dari hal tersebut di atas, maka peneliti tertarik untuk mengkaji tentang pemikiran KH. Said Aqil Siroj tentang pendidikan multikultural dalam bingkai Islam Nusantara. Novelty penelitian ini terletak pada upaya untuk mengungkap realitas pemikiran tokoh nasional dalam upaya menciptakan persatuan dan kesatuan bangsa melalui konsepsi Islam Nusantara, dengan harapan akan tercipta Negara yang baldatun thoyyibatun wa rabbun ghafur.

\section{Biografi Singkat KH. Said Aqil Siroj}

Kiai Said hidup di kalangan keluarga berkultur pesantren. Abah beliau merupakan perintis pondok pesantren Tarbiyatul Mubtadiin yang berada di daerah Kempek Cirebon. Beliau termasuk orang yang sangat berkharismatik. Keluarga Kiai Said merupakan kalangan keluarga yang sangat memperioritaskan pendidikan, ${ }^{11}$ sehingga sekolah beliau tidak berhenti di jenjang S1 bahkan sampai menyelesaikan pendidikan S3.

Beliau mempelajari dasar ilmu keIslaman dengan ayahanda tercinta di pesantren. Pesantren merupakan potret jalinan kehidupan masyarakat luas selain itu, terdapat sekelompok masyarakat yang beraneka ragam. ${ }^{12}$ Lingkungan pesantren mengajarkan Kiai Said sebagai orang yang bertoleransi, menghormati yang tua, menyayangi yang muda. Sikap ini, bila dirangkai dalam bingkai pendidikan, apalagi dalam bingkai Nusantara, sungguh akan menyejukkan hati dan menjadikan Negara ini sebagai Negara yang aman, makmur serta santosa. ${ }^{13}$

Pendidikan awal beliau di pesantren abahnya yang memiliki ciri khas Salaf. Kemudian, beliau mempelajari ilmu formal di Sekolah Rakyat. Setelah itu, perjalanan studynya di Pondok Pesantren KH. Mahrus Ali "PP Hidayatul Mubtadiin" di Lirboyo Kediri sejak jenjang Tsanawiyah hingga Aliyah berkisaran 1965-1970. Kemudian tepatnya 1972 beliau meneruskan perjalananya ke "PP Al Munawwir" KH. Ali Ma'sum daerah

\footnotetext{
${ }^{11}$ Muhammad Dewan Sukardi, “ Dari Pesantren Untuk Bangsa; Kado Buat Kiyai Said” in NU Sejak Lahir (Jakarta: SAS Center, 2010), 2.

12 Syuhud Syuhud, 'Partisipasi Dalam Pengambilan Keputusan Strategis Di Pondok Pesantren', Al-Tanzim: Jurnal Manajemen Pendidikan Islam, 3.2 (2019), 37-48 $<$ https://doi.org/10.33650/al-tanzim.v3i2.658>.

13 Imam Fathurohman, 'Islam Nusantara Dalam Pemikiran KH. Said Aqih Siraj Dan Usaha Sosialisasinya Tahun 2010-2018 M' (Universitas Islam Negeri Sunan Kalijaga, 2018). 19
} 
Krapyak Jogjakarta hingga tahun $1975 .{ }^{14}$ Tidak berhenti disitu perjalanan beliau namun, beliau masih menimba ilmu di Universitas King Abdul Aziz (cabang Makkah) bidang pendidikan Ushuluddin dan Dakwah. Tahun 1982 beliau melanjutkan ke jenjang magister. Tahun 1994 beliau telah menuntaskan pendidikan jenjang doktor di Universitas Ummu Quro bidang studies Perbandingan Agama.

Setelah itu, beliau pulang ke Indonesia, dan saat itu pula beliau langsung diangkat sebagai Wakil Katib Syuriah di PBNU. Selama di kepengurusan PBNU, Kiai Said sering menuturkan wacana yang kontroversial. Sampai-sampai dianggap berani dan keluar dari pakem ortodoksi oleh kalangan masyarakat Nahdliyin yang mayoritas warganya bercorak konservatif. Bahkan, sekitar 12 Kiai yang mengibaratkan beliau kafir tetapi, ketika diadakan tabayyun yang dihadiri oleh para Kiai NU, tampaklah ilmu, ideologi dan pengetahuan luas beliau tentang Islam. ${ }^{15}$

Pandangan ulama terdahulu tentang relevansi agama dan negara sampai saat sekarang dijaga, dilestarikan serta dibudidayakan oleh generasi ulama NU dibawah komando Kiai Said. Telah ditegaskan bahwa sikap NU adalah tetap konsisten dan berkomitmen pada UUD 1945 dan Pancasila. ${ }^{16} \mathrm{Hal}$ itu, memberikan contoh dan mengajarkan sikap toleran dan nasionalis serta tetap berpegangan pada semboyan Bbieneka Tunggal Ika.

Kiai Said selain menjabat sebagai pengurus NU beliau termasuk seorang pendakwah yang menyandang visi dan misi tersendiri dalam menjadikan Indonesia sebagai negeri berbudaya, makmur dan tentram. Sudah sangat jelas sekali bahwa aktivitas kesehariannya, beliau mengaktualikasikan pemikiran dakwahnya, ${ }^{17}$ karena pada hakikatnya dakwah merupakan ikhtiar untuk mengajak kepada kedamaian, kebaikan secara menyeluruh, baik mengajaknya secara personal mapun sosial baik dengan tulisan, ucapan maupun tingkah laku. ${ }^{18}$

\footnotetext{
${ }^{14}$ Farista Zulfa Khasanah, 'Studi Pemikiran Said Aqiel Siradj Tentang Kesetaraan HakHak Politik Perempuan Untuk Menjadi Kepala Negara' (UIN Walisongo Semarang, 2018). 76

${ }^{15}$ Imam Fathurohman, "Islam Nusantara dalam Pemikiran K.H Said Aqil Siradj dan Usaha-Usaha Sosialisasinya tahun 2010-2018,” in Skripsi, 2018,1-51.

${ }^{16}$ Amin Fatih, "Konsistensi Nahdlatul Ulama' dalam Mempertahankan Pancasila dan Kedaulatan Negara Kesatuan Republik Indonesia di Tengah Wacana Negara Islam," $\begin{array}{lllll}\text { Jurnal Politik } & \text { Walisongo, } & 1.1 & \text { (2019), }\end{array}$ <https://doi.org/10.21580/jpw.2019.1.1.2026>.

${ }^{17}$ Luluatu Nayiroh, "Pemikiran dan Aktivitas Dakwah Prof. Dr. K.H Said Aqil Siroj," in Skripsi, 2013, 1-123.

18 Dalinur. M. Nur, "Dakwah Teori, Definisi dan Macamnya,"Jurnal Wardah, 23, (2011),1-7.
} 


\section{Hakikat Pendidikan Multikultural}

Makna multukulturalisme secara etimologis bermacam-macam. Diantaranya adalah sebuah doktrin yang membenarkan adanya beberapa kultur. Multukulturalisme berasal dari kata multi yang bermakna banyak, cultur bermakna budaya, dan isme adalah sebuah aliran dan paham. Karenanya multukulturisme dipandang dari segi fungsinya dapat dijadikan sebagai wahana untuk memperbaiki taraf hidup dan gaya hidup manusia. $^{19}$

Dengan demikian, setiap orang dengan adanya konsep multikultural ini merasa dihargai sekaligus merasa bertanggung jawab untuk tetap hidup bersama komunitasnya.

Pendidikan multikutural dalam istilah dipahami sebagai instrument yang membahas sebuah kebhinekaan budaya dalam merespon perubahan berdasarkan lingkungan khusus atau dunia secara global. Hal ini menunjukkan bahwa pendidikan multikultural merupakan usaha secara sungguh-sungguh melalui pendidikan dalam memperhatikan hikayat hidup belajar dari aspek agama, etnis, serta kultur yang berbeda. ${ }^{20}$ Sedangkan Lu'lu' Nurhusna menyatakan bahwa pendidikan multikultural merupakan badal dari pendidikan interkultural dengan adanya harapan supaya dapat memelihara sikap pegertian dan afeksi terhadap sesama seperti halnya toleransi, diskriminasi, pluralitas, demokrasi. ${ }^{21}$

Pendidikan multicultural bergelut pada pemahaman budaya seseorang, penilaian, penghargaan keingin tahuan etnis seseorang serta penghormatan. ${ }^{22}$ Ruang geraknya meliputi penilaian-penilain kepada lintas budaya dalam arti mencoba meneliti cara kebudayaan khusus atau tertentu yang dapat mengungkapkan nilai tersendiri bagi anggotanya.

Apabila multikulturalisme hanya suatu wacana kebudayaan (pengembangan identitas) maka, butuh identitas dari negara bersangkutan. Suatu bangsa mampu menata dan memperkukuh jika sadar akan adanya power yang tak mungkin goyah. ${ }^{23}$ Jaminan berlangsungnya hidup rakyat serta perkembangannya dengan cara mengikatnya dengan

19 Parsudi Suparlan, "Menuju Masyarakat Indonesia yang Multikultural," Jurnal Antropologi Indonesia, (2002), 1-8.

${ }^{20}$ Imam Mahalli Musthofa, "Pendidikan Islam dan Tantangan Globalisasi," (Ar Ruzz Media, 2004), 264.

${ }^{21}$ Lu'lu' Nurhusna, Multukulturalisme Azyumardi Azra dan Relevansinya dengan Pendidikan Islam, in Skripsi, (2014), 1-67.

22 Rustam Ibrahim, "Pendidikan Multikultural : Pengertian, Prinsip, dan Relevansinya dengan Tujuan Pendidikan Islam," Jurnal Addin,7.1 (2013), 1-26.

${ }^{23}$ Mudzier Suparta, "Islamic Multicultural Education,” (Al Ghazali Center, 2008), 37. 
kehidupan yang damai dan sejahtera.

Pendidikan multikultural berarti gagasan kontekstual dengan realitas masyarakat modern seperti saat ini. Pijakan kesetaraan, keterbukaan, keadilan, menerima perbedaan termasuk unsur yang dibutuhkan masyarakat globalisme yang banyak tantangan. Multikultural berkedudukan sebagai konsep majemuk yaitu bangsa yang dipenuhi dengan keberagamaan budaya. ${ }^{24}$

Pendidikan multikultural adalah ikhtiyar alternatif pengelola kehidupan antar insan yang tersistem. Tujuan pendidikan multikultural adalah menciptakan sebuah hubungan inovatif dan serasi dengan penduduk. ${ }^{25}$ Implementasi pendidikan multikultural di semua sekolah ataupun madrasah termasuk urgen, karena para pelajar diajak dan diperkenankan membangun solidaritas, toleransi, musyawarah bersama. ${ }^{26}$

\section{Potret Multukulturalisme di Indonesia}

Islam Nusantara merupakan dua gabungan kata dari kata Islam dan Nusantara. Islam Nusantara bukanlah aliran baru, bukan pula termasuk sekte baru, melainkan sebuah tipologi atau ciri khusus tentang ekspresi keberadaan umat Nusantara, di mana nilai-nilai keIslamannya telah menjalar melalui budaya setempat. Bukan pula faham baru yang mempersempit atau bahkan sampai mengubah isi kebenaran fatwa-fatwa Islam universal dan sakral. ${ }^{27}$ Melainkan sebagai cara penerapan kandungan agama Islam untuk diaplikasikan masyarakat Nusantara sehingga menjadi budaya, tradisi Islami dan siasat aktualisasi Islam di kalangan Nusantara yang tetap melanggengkan prinsip pokok yang kembali pada acuan Islam yakni Al Qur'an dan Hadist.

Tokoh yang mengikhtiyarkan adanya konsep Islam Nusantara adalah KH. Said Aqil Siroj. Menurutnya "kita perlu mempertahankan kelestarian budaya selama tidak meleset dari koredor syari'at dan tidak perlu lagi dipertentangkan. Islam yang harmonis dengan budaya, Islam yang menghargai budaya itulah Islam Nusantara". ${ }^{28}$ Hal tersebut berdasarkan pada fakta histori masuknya Islam di Nusantara dan

\footnotetext{
24 Ibrahim.

25 Hasan Baharun dan Robiatul Awwaliyah, "Pendidikan Multikultural dalam Menanggulangi Narasi Islamisme di Indonesia," Jurnal Pendidikan Agama Islam (Journal of Islamic Education Studies). 5.2 (2017), 1-20.

${ }^{26}$ M.Nadlir.

${ }^{27}$ Khabibi Muhammad Luthfi, "Islam Nusantara: Relasi Islam dan Budaya Lokal," Jurnal Shabih, 1.1 (2016), 1-12.

28 Taufik Bilfagih, "Islam Nusantara; Strategi Kebudayaan NU di tengah Tantangan Global,” Jurnal Aqlam, 2. 1 (2016), 1-16.
} 
berdasarkasn pemikiran K.H Hasyim Asy'ari dan K.H Abdurrahman Wahid serta dakwah Walisongo. Jadi, Islam Nusantara menurut pandangan Kiai Said adalah aktivias berkesinambungan antara semangat nasionalisme dengan Islam yang masih melestarikan variasi budaya selama ini. Ini telah dipaparkan di depan khalayak ramai.

Kehidupan Islam toleran di Indonesia yang beradab dan moderat ini, masih kuat sekali dengan asal usul adanya Islam. Terobosan Walisongo untuk membumikan Islam ialah melalui dakwah. Namun, mereka tetap berkonsisten menjaga ada istiadat pribumi. Model Islam Nusantara artinya peleburan tradisi setempat dan budaya Islam.

Keadaan dunia pada saar ini sedang diresahkan oleh turunnya nilainilai kemanusiaan serta banyaknya kericuhan seperti di daerah Timur Tengah. Banyak kelompok yang mengatasnamakan Islam, namun perilaku mereka sangat tidak senada dengan ajaran sya'riat Islam yang dibawa utusan. ${ }^{29}$ Maraknya aliran garis keras dan teroris yang mengatasnamakan Islam membuat nama reputasi Indonesia menjadi buruk di hadapan dunia. ${ }^{30}$ Sekalipun peristiwa tersebut mencoreng nama baik Indonesia, Kiai Said tetap berusaha dan tetap berupaya merawat serta melestarikan Islam Nusantara, dengan mengembangkan pondok pesantren, menjadikan konsep muktamar NU ke-33 dan menyebar luaskan ke berbagai forum bahkan sampai internasional. ${ }^{31}$

Di Timur Tengah, Islam sering kali digolongkan gerakan keras tanpa toleransi, sehingga membuat umat muslim dunia malu serta takut melihat realita ini. Ini melahirkan pandangan negative terhadap Islam. Peristiwa itu disebut Islamphobia. ${ }^{32}$

\section{Paradigma Said Aqil terhadap Pendidikan Multikultural dalam Bingkai Islam Nusantara}

Indonesia memiliki keberanekaragaman agama, suku, bangsa dan budaya. Keanekaragaman tersebut termasuk modal besar pembentuk masyarakat multikultural, jika masyarakatnya saling toleran serta hidup beriringan. Adanya pengelolaan terhadap perbedaan sangatah urgen, karena tanpa pengelolaan yang benar, keragamaan yang semula merupakan rahmat serta modal pembangun kesatuan bangsa, akan

\footnotetext{
${ }^{29}$ Luthfi.

${ }^{30}$ Edi Susanto \& Moh. Mashur Abadi, "Pesantren and The Preservation Of Islam Nusantara," Jurnal Sosial dan Budaya Keislaman, 23.2 (2015), 1-15.

${ }^{31}$ Saiful Mustofa, "Meneguhkan Islam Nusantara untuk Islam Berkemajuan," Jurnal Episteme, 10. 2 (2015), 1-30.

${ }^{32}$ Edy Susanto Karimulah, "Islam Nusantara: Islam Khas dan Akomodasi terhadap Budaya Lokal," Jurnal Al-Ulum, 1.1 (2016), 1-25.
} 
berubah memicu runtuh dan hancurnya integrasi bangsa. Urgensi pendidikan sangatlah mutlak sepanjang hayat, ${ }^{33}$ karena pendidikan bisa mengantarkan seseorang dapat membuka dunia, menemukan kebahagiaan dan kesejahteraan.

Sebagai organisasi yang memiliki basis massa terbesar di Indonesia, NU memiliki kendali penuh dalam kegiatan pendidikan, lebih-lebih yang berbasis pesantren di bawah kendali lembaga Ma'arif. ${ }^{34}$ Konsistensi visi dan misi NU belum pernah berubah sejak berdirinya NU sampai saat ini, yaitu; Islam tawassuth (moderat), tasamuh (toleransi) dan mempunyai citacita tinggi agar selalu dapat memperkuat tiga persaudaraan ukhwah Islamiyah, ukhwah wathoniyah dan ukhwah basyariyah .

Kondisi muslim dewasa ini, sangat menghawatirkan dikarenakan sebagian kelompok memiliki pemahaman radikal, sebagian lainnya menjadi teroris. Radikalisme menyerang Indonesia dari berbagai belahan, diantaranya menyerang ideologi umat Islam. Ketika radikal telah meracuni ideology umat, maka sangatlah sulit sekali untuk dihilangkan. Akan tetapi, hal itu masih bisa diantisipasi melaluli pengkaderan. Para remaja yang steril akan faham radikalisme benar-benar harus dijaga ideologinya. Itulah aksi Kiai Said demi terjaganya keharmonisan negara ini. ${ }^{35}$

Ketika faham radikalisme bertolak belakang dengan konteks keindonesiaan maka, pertama yang akan dilakukan oleh Kiai Said adalah mengadakan sosialisasi pemahaman pancasila ${ }^{36}$ dan disosialisasikan oleh BPIP (Badan Pengamalan Ideologi Pancasila) kepada seluruh rakyat Indonesia. Kedua, mengantisipasi faham warga NU dan memberi khazanah lebih dalam tentang kebenaran Islam sesungguhnya, agar pemikiran faham radikalisme yang merusak bangsa tersingkirkan. Ketiga, melibatkan organisasi Islam sebagai penangkal radikalisme. Keempat, meminta seluruh elemen-elemen bangsa agar tetap terus memperhatikan persatuan bangsa dengan konsisten melestarikan budaya dan akhlaknya.

Menurut pandangan KH. Said Aqil Siroj, pendidikan multikultural dalam bingkai Islam Nusantara memiliki peran yang sangat penting dan strategis dalam menjaga integrasi kesatuan bangsa Indonesia, ${ }^{37}$ yaitu;

33 Hefniy, "Membangun Pendidikan Berbasis Islam Nusantara," Jurnal Islam Nusantara, 1.1 (2017), 1-7.

34 Ali Rahim, "Nahdlatul Ulama (Perananan dan Sistem Pendidikannya)," Jurnal Al Hikmah, XIV (2013), 2013.

35 "Akal Said Aqil" di Youtube https://www.youtube.com/watch?v=TPmwXkrXF4

36 Akal Said Aqil

${ }^{37}$ Nurul Hidayati, "Konsep Pendidikan Islam Berwawasan Multikulturalisme Perspektif HAR.Tilaar," Jurnal Pendidikan Agama Islam, 4.1 (2016), 1-24. 
sebagai sarana penanganan masalah, bertahannya peserta didik dengan kulturnya, landasan pengembangan kurikulum.

Pendidikan multikultural dalam bingkai Islam Nusantara, menurut KH. Said Aqil Siroj dapat dilaksanakan dengan cara;

Pertama menggerakkan dan mengoptimalkan peran Kiai di masyarakat. Kiai tak hanya alim, tetapi mereka menjadi panutan masyarakat dan memandang umat dengan kasih dan ramah. Artinya Kiai merupakan leader informal yang membimbing masyarakat dengan kedekatan. Kehidupan Kiai bersinggungan dengan masyarakat, sosok penyelamat masyarakat dari penyimpangan-penyimpangan pemahaman agama, pendidikan maupun konteks kebangsaan. Itu semua menjadi tugas serta peran para Kiai. ${ }^{38}$

Keberhasilan pesantren bergantung kepada kedalaman dan keahlian ilmu Kiai, kharismatiknya dan wibawanya. ${ }^{39}$ Karena itu Kiai merupakan figure central di lingkungan pesantren. Untuk meningkatkan kualitas pesantren maka, mengoptimalkan peran Kiai termasuk jalan pintas terbaik. ${ }^{40}$ Di internal masyarakat NU, para masyayikh hendaknya menyampaikan pentingnya akhlak dalam menyikapi perbedaan. Dengan akhlak diri seseorang dapat terkontrol. Tujuan lainnya yakni mengikis angka percekcokan, pertikaian dan konflik antar umat Islam. Keharmonisan keluarga tetap terjaga karena terlahir manusia-manusia bertoleran.

Kedua, penguatan kurikulum pada lembaga pendidikan Islam. Kurikulum merupakan barometer untuk mengukur tercapainya harapan pendidikan yang merupakan panduan KBM di semua tingkat satuan pendidikan. ${ }^{41}$ Konsekuensinya adalah harus mengelolanya dengan maksimal agar outputnya juga cemerlang. Pengelolaan kurikulum perlu meninjau tinjauan praktis dan teoritis agar berjalan demi mengimbangi teknologi, kehidupan manusia dan ilmu pengetahuan. ${ }^{42}$ Kurikulum pendidikan hendaknya diorientasikan pada pembentukan karakter peserta

\footnotetext{
38 Sayfa Auliya Achidsti, "Eksistensi Kiai dalam Masyarakat," Jurnal Kebudayaan Islam, 12. 12 (2014), 1-23.

39 Wiwin Fitriyah, Abd Hamid Wahid, dan Chusnul Muali, "Eksistensi Pesantren dalam Pembentukan Kepribadian Santri," Jurnal Studi Keislaman dan Ilmu Pendidikan, 1. 2 (2018), $1-19$.

40 Zaini Hafidh, "Peran Kepemimpinan Kiai dalam Peningkatan Kualitas Pondok Pesantren di Kabupaten Ciamis," Jurnal Administrasi Pendidikan, XXIV. 2 (2017), 1-7.

${ }^{41}$ Akhmad Saufi and Hambali, 'Menggagas Perencanaan Kurikulum Menuju Sekolah Unggul', Al-Tanzim: Jurnal Manajemen Pendidikan Islam, 3.1 (2019), 29-54.

42 Razali M. Thaib \& Irman Siswanto, "Inovasi Kurikulum dalam Pengembangan Pendidikan,” Jurnal Edukasi,1. 2 (2015), 1-13.
} 
didik yang toleran, humanis dan mampu menghargai perbedaan yang ada di sekitarnya.

Ketiga, menggerakkan generasi bangsa yang langsung dibimbing serta dibina oleh Kiai-Kiai NU sangatlah efektif, karena dapat mempertaruhkan asas agama berbasis Aswaja An-Nahdliyin dan patriotisme santri. Ketika ideologi mereka kuat maka, tangguh akan paham-paham baru yang ingin melengserkan kebenaran sejati. Jantungnya organisasi adalah pengkaderan. Artinya, hidup matinya sebuah organisasi disetir oleh kaderisasinya. Ketika tidak ada pengkaderan niscaya akan merobohkan organisasi. Peran kaderisasi dalam memelihara solidaritas organisasi sangatlah urgen, khususnya dalam membuka inklusivitas dalam beragama, menghargai dinamika perbedaan dan hidup dalam masyarakat yang multicultural.

Keempat, menanamkan dan mengajarkan sikap nasionalisme kepada masyarakat. Satu-satunya ulama yang memiliki jargon Hubbul Wathon minal Iman (nasionalisme bagian dari iman) di dunia adalah K.H Hasyim Asy'ari pendiri NU. Sangat jelas sekali bahwa para ulama' NU jauh hari, sebelum kemerdakaan, sudah memikirkan rasa patriot terhadap bangsa. Seperti itulah didikan yang diajarkan ulama, tetap mempertahankan sikap toleransi kepada warganya. Pendidikan multicultural dalam dinamika Islam Nusantara berusaha untuk menyelaraskan budaya dan agama agar berdampingan tanpa saling menyalahkan bahkan saling menjatuhkan melalui aktivitas pendidikan.

Islam Nusantara sebagai pelopor bangsa yang menganut Islam agar mencintai tanah kelahirannya, dengannya akan mewujudkan peradaban dikarenakan peradaban suatu agama \& bangsa akan terealisasi dengan wujudnya tanah air. Bangsa Indonesia menekankan pemahaman terhadap multi ras, multi etnis, multi kultur yang membutuhkan kontruksi dan paradigma baru atas kesetaraan, keselarasan serta menciptakan demokrasi bangsa, serta direspon baik untuk memelihara kesatuan dan keutuhan bangsa mutikultur ini. Pernyataan yang dipaparkan beliau menunjukkan bahwa KH. Said Aqil mendukung terhadap pengaplikasian pendidikan multikultural di bumi Nusantara ini. Eksitensi pendidikan multikultural adalah kebutuhan mendesak dan harus segera direalisasikan.

\section{KESIMPULAN}

Masyarakat majemuk dan plural terpotret di negeri ini. Untuk tetap menjaga eksitensi keharmonisan sesama manusia setanah air, maka sikap toleransilah yang selayaknya diterapkan. Semboyan kebangsaan tetap harus dipertahankan yaitu Bhineka Tunggal Ika (bersatu kita teguh, bercerai kita berantakan). Ini termasuk dari upaya memahami keberagaman manusia yang melalui pendidikan. Melalui bermacam- 
macam budaya, perlu kiranya mengembangkan dan mengimplementasikan pendidikan multikulural.

Motif pendorong Kiai Said menerapkan pendidikan multikultural diantaranya adalah; menyebarnya faham radikal dan terorisme, merosotnya toleransi ummat Islam, seringnya terjadi konflik. Dalam rangka mensukseskan pendidikan multikulural dalam bingkai Islam Nusantara, upaya yang telah dilakukan adalah; memanfaatkan peran Kiai, menguatkan kurikulum pendidikan, menggerakkan pengkaderan dan menanamkan semangat nasionalis kepada masyarakat. 


\section{DAFTAR PUSTAKA}

Abadi, Edi Susanto \& Moh. Mashur, 'Pesantren And The Preservation Of Islam Nusantara', Jurnal Sosial Dan Budaya Keislaman, Vol. 23.No. 2 (2015), $1-15$ $<$ https://doi.org/10.19105/karsa.v2312.718>

Abdurahman, 'Implikasi UUSPN Terhadap Pendidikan Islam', AlTanzim : Jurnal Manajemen Pendidikan Islam, 1.1 (2017), 19-35

Achidsti, Sayfa Auliya, 'Eksistensi Kiai Dalam Masyarakat', Jurnal Kebudayaan Islam, Vol. 12.No. 12 (2014), 1-23

Ambarudin, R. Ibnu, 'Pendidikan Multikultural Untuk Membangun Bangsa Yang Nasionalis Religius', Jurnal Civis, Vol. 13.No. 1 (2016), 1-18

Baharun, Hasan, and Robiatul Awwaliyah, 'Pendidikan Multikultural Dalam Menanggulangi Narasi Islamisme Di Indonesia', Jurnal Pendidikan Agama Islam (Journal of Islamic Education Studies), Vo. 5.No. 2 (2017), 1-20

Bilfagih, Taufik, 'Islam Nusantara; Strategi Kebudayaan NU Di Tengah Tantangan Global', Jurnal AQLAM, Vol. 2.No. 1 (2016), 1-16

Dalinur.M.Nur, 'Dakwah Teori, Definisi Dan Macamnya', Jurnal Wardah, No. 23, 2011, 1-7

Fadlullah, Muhammad Endy, 'Ahlu Al-Sunnah Wa Al-Jamaah Dalam Perspektif Said Aqil Siradj’, Jurnal Nidhomul Haq, Vol. 3.No. 1 (2018), 1-11

Faisol, M., 'Peran Pondok Pesantren Dalam Membina Keberagaman Santri', Al-Tanzim: Jurnal Manajemen Pendidikan Islam, 1.2 (2017), 37-51 <https://doi.org/10.1017/CBO9781107415324.004>

Fathurohman, Imam, 'Islam Nusantara Dalam Pemikiran K.H Said Aqil Siradj Dan Usaha-Usaha Sosialisasinya Tahun 2010-2018', in Skripsi, 2018, pp. 1-51

Fatih, Amin, 'Konsistensi Nahdlatul Ulama' Dalam Mempertahankan Pancasila Dan Kedaulatan Negara Kesatuan Republik Indonesia Di Tengah Wacana Negara Islam', Jurnal Politik Walisongo, 1.1 (2019), 1-20 <https://doi.org/10.21580/jpw.2019.1.1.2026>

Fitriyah, Wiwin, Abd Hamid Wahid, and Chusnul Muali, 'Eksistensi Pesantren Dalam Pembentukan Kepribadian Santri', Jurnal Studi Keislaman Dan Ilmu Pendidikan, Vol.No. 2 (2018), 1-19

Hafidh, Zaini, 'Peran Kepemimpinan Kiai Dalam Peningkatan Kualitas

Pondok Pesantren Di Kabupaten Ciamis', Jurnal Administrasi Pendidikan, Vol. XXIV.No. 2 (2017), 1-7

Hefniy, 'Membangun Pendidikan Berbasis Islam Nusantara', Jurnal Islam 
Nusantara, Vol. 01.No. 01 (2017), 1-7

Hidayati, Nurul, 'Konsep Pendidikan Islam Berwawasan Multikulturalisme Perspektif HAR.Tilaar', Jurnal Pendidikan Agama Islam, Vol. 4.No. 1 (2016), 1-24

Ibrahim, Rustam, 'Pendidikan Multikultural: Pengertian, Prinsip , Dan Relevansinya Dengan Tujuan Pendidikan Islam', Jurnal ADDIN, Vol. 7.No. 1 (2013), 1-26

Irwandi, Endah R. Chotim, 'Analis Konflik Antara Masyarakat,Pemerintah Dan Swasta', Jurnal JISPO, Volume 7.No 2 (2017), 1-20

Karimulah, Edy Susanto, 'Islam Nusantara : Islam Khas Dan Akomodasi Terhadap Budaya Lokal', Jurnal Al-Ulum, Vol. 1.No. 1 (2016), 125

Khasanah, Farista Zulfa, 'Studi Pemikiran Said Aqiel Siradj Tentang Kesetaraan Hak-Hak Politik Perempuan Untuk Menjadi Kepala Negara' (UIN Walisongo Semarang, 2018)

Luthfi, Khabibi Muhammad, 'Islam Nusantara : Relasi Islam Dan Budaya Lokal', Jurnal Shabih, Vol. 1.No. 1 (2016), 1-12

M.Nadlir, 'Pendidikan Multikultural Dalam Perspektif Said Agil Husin Al Munawwar', Jurnal Pendidikan Agama Islam, Vol. 01.No. 01 (2013), $1-17$

Muali, Chusnul, 'Rasionalitas Konsepsi Budaya Nusantara Dalam Menggagas Pendidikan Karakter Bangsa Multikultural', Jurnal Islam Nusantara, Vol. 01.No. 01 (2017), 1-13

Musthofa, Imam Mahalli, 'Pendidikan Islam Dan Tantangan Globalisasi', in Buah Pikiran Seputar Fisafat, Politik, Ekonomi, Sosial Dan Budaya (ar Ruzz Media, 2004), p. 264

Mustofa, Saiful, 'Meneguhkan Islam Nusantara Untuk Islam Berkemajuan', Jurnal Episteme, Vol. 10.No. 2 (2015), 1-30

Nayiroh, Luluatu, 'Pemikiran Dan Aktivitas Dakwah Prof. Dr. K.H Said Aqil Siroj', in Skripsi, 2013, pp. 1-123

Nurhusna, Lu'lu', Multukulturalisme Azyumardi Azra Dan Relevansinya Dengan Pendidikan Islam, Skripsi, 2014, pp. 1-67

Rahim, Ali, 'Nahdlatul Ulama (Pernanan Dan Sistem Pendidikannya)', Jumal Al Hikmah, XIV (2013), 2013

Ramayulis, Ilmu Pendidikan Islam ((Jakarta: Kalam Mulia, 2002)

Sada, Heru Juabdin, 'Peran Masyarakat Dalam Pendidikan Perspektif Pendidikan Islam', Jurnal Al-Tadrkizyah, Vol. 8.No.I (2017), 1-9

Saufi, Akhmad, and Hambali, 'Menggagas Perencanaan Kurikulum Menuju Sekolah Unggul', Al-Tanzim: Jurnal Manajemen Pendidikan Islam, 3.1 (2019), 29-54 
Setiawan, Eko, 'Pemikiran Abdurrahman Wahid Tentang Prinsip Pendidikan Islam Multikultural Berwawasan Keindonesiaan', Jurnal Pendidikan Islam, Vo.2.No.1 (2017), 1-14

Siswanto, Razali M. Thaib \& Irman, 'Inovasi Kurikulum Dalam Pengembangan Pendidikan', Jurnal Edukasi, Vol. 1.No. 2 (2015), $1-13$

Suparlan, Parsudi, 'Menuju Masyarakat Indonesia Yang Multikultural', Jurnal Antropologi Indonesia, 2002, 1-8

Suparta, Mudzier, 'Islamic Multicultural Education', in Sebuah Refleksi Atas Pendidikan Agama Islam Di Indonesia (Al Ghazali Center, 2008), p. 37

Syuhud, Syuhud, 'Partisipasi Dalam Pengambilan Keputusan Strategis Di Pondok Pesantren', Al-Tanrim: Jurnal Manajemen Pendidikan Islam, 3.2 (2019), 37-48 <https://doi.org/10.33650/altanzim.v3i2.658>

Wihardit, Kuswaya, 'Pendidikan Multikultural: Suatu Konsep, Pendekatan Dan Solusi', Jurnal Pendidikan, Vol. 11.No.11 (2010), $1-10$ 